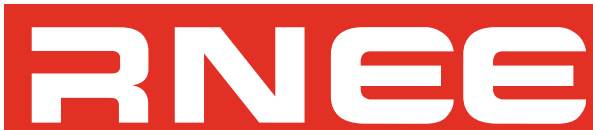

Revista Nicolaita de Estudios Económicos

Nueva Época

Instituto de Investigaciones Económicas y Empresariales
Universidad Michoacana de San Nicolás de Hidalgo

Volumen XV, Número 2, Julio - Diciembre 2020, pp. 11-30

ISSN (Print): 1870 - 5464 ISSN (On-line): 2007 - 9877

DOI: $10.33110 /$ rnee.v15i2.313

(Recibido: 26/mayo/2020; Aceptado: 27/septiembre/2020)

\title{
Inversión Extranjera Directa en el contexto de apertura y liberalización económicas en México y China (1978-2016)
}

\section{Foreign Direct Investment in the context of economic openness and liberalization in Mexico and China (1978-2016)}

\author{
María Isabel Hernández Aceves a \\ Magnolia Miriam Sosa Castro b*
}

\section{Resumen}

En el marco de los procesos de liberalización económica y apertura comercial, y ante los disimiles resultados obtenidos por la economía china y mexicana, el objetivo del presente trabajo es analizar, una variable clave para el crecimiento económico: la Inversión Extranjera Directa (IED) y los factores determinantes de la misma, para ambas economías de 1978 y hasta 2016. La principal conclusión es que, el impacto de la (IED) en la actividad económica, ha dependido de cómo se ha llevado a cabo el proceso de apertura económica y las reformas para la atracción de capitales extranjeros.

Palabras claves: IED, China, México, reforma estratégica, apertura comercial, liberalización.

Clasificación JEL: F21; P33; P45; E22

\begin{abstract}
In the economic liberalization and trade openness context, and as a result of unlike economic performance in Mexican and Chinese economies, the aim of this research is to analyze a key factor for economic growth: Foreign Direct Investment (FDI) and its determinant factors, in both economies from 1978 to 2016. The main conclusion is that, the FDI impact in economic activity relays on how the economic openness process and the foreign capital attraction reforms have been developed.
\end{abstract}

Keywords: FDI, China, Mexico, strategic reform, trade openness, liberalization

JEL Codes: F21; P33; P45; E22

\footnotetext{
$\bar{a}$ Egresada de la Facultad de Economía, UNAM. Email: isabelhdezunam@gmail.com

b Departamento de Economía, Universidad Autónoma Metropolitana-Iztapalapa. Email: msosac87@hotmail.com

* Autor de correspondencia
} 


\section{Introducción}

En el contexto del nuevo orden económico, la globalización y liberalización económica se presentan como fenómenos que promueven la interconexión comercial, el incremento y aumento de los movimientos de capital y la creciente dependencia a nivel mundial. La respuesta inmediata a este proceso de liberalización fue un incremento del flujo de IED; la llegada de capital extranjero tiene múltiples efectos: eleva la competitividad y el comercio a nivel mundial, funge como medio de trasferencia tecnológica, eleva las oportunidades de empleo y desarrollo de capital humano, sirve como flujo de capital adicional para necesidades de financiamiento, entre otros.

El presente tiene por objetivo analizar la Inversión Extranjera Directa (IED) y los factores determinantes de la misma, como un factor clave para explicar el diferencial en el crecimiento económico de México y China durante el periodo 1978-2016. El análisis se desarrolla empleando una rigurosa metodología teórica-descriptiva.

La hipótesis que se desprende de la investigación es que, el impacto de la Inversión Extranjera Directa en la actividad económica, depende de cómo se desarrollaron los procesos de apertura económica y las reformas enfocadas en la atracción de capitales, así como, la asimilación de dichos procesos al interior de las economías.

Así, las economías en estudio parten de un mismo punto; tanto México como China, a finales de la década de los setenta, impulsan una serie de políticas similares, para después originarse una brecha de crecimiento económico que, a la fecha, continúa pronunciándose. En este contexto, se resalta el constante interés por explicar el rezago y pobre desempeño económico de México, una economía emergente con potencial manejada por intereses externos.

Cabe señalar que, la presente investigación se suma a los trabajos previamente desarrollados en torno al análisis de Inversión Extranjera Directa en las economías bajo estudio, entre los que destacan: Sánchez Ortiz (2018) que examina los determinantes de la IED en México y China, resaltando la importancia de las políticas e instituciones desarrolladas en ambos países; Duana Ávila y Hernández Mendoza (2012) mencionan el papel de las ventajas comparativas entre ambos países, de manera específica, programas, reformas, estrategias e incentivos de fomento para la IED (Inversión Extrajera Directa) y; Chiñas y García (2017) que complementan el análisis desde el enfoque de las cadenas globales de valor y el papel que la economía mexicana y china juega en dichos procesos.

La contribución de la investigación radica en evidenciar las divergencias que existieron en el proceso de apertura económica y en las reformas enfocadas a la atracción de capital extranjero entre México y China. Así como, en analizar el impacto de dichas divergencias en los factores determinantes de la IED en cada país, permitiendo rescatar las experiencias previas y retomando algunas lecciones respecto a la promoción de la economía mexicana.

El trabajo se encuentra dividido en cuatro secciones además de la presente, la segunda presenta el análisis y evolución de los aspectos macroeconómicos y comerciales de China y México, la tercera sección estudia los factores determinantes de la inversión extranjera directa en ambos países y la cuarta sección concluye el trabajo con comentarios y reflexiones finales. 


\section{Evolución macroeconómica y apertura comercial: comparativa entre México y China (1978- 2016)}

\subsection{Evolución de la actividad económica}

La economía china y mexicana en los años setenta mostraban similitudes. La brecha entre estos países comienza, especialmente, a partir de 1982, como resultado de las políticas de China instauradas a partir de 1978 dirigidas a la apertura externa impuestas por su nuevo líder, Deng Xiapong, mientras que, México se centró en la privatización de la actividad productiva y, de igual manera, en convertirse en una economía aperturista, tanto comercial, como financiera, irrestrictamente.

Gráfica 1

Brecha de crecimiento económico entre China y México

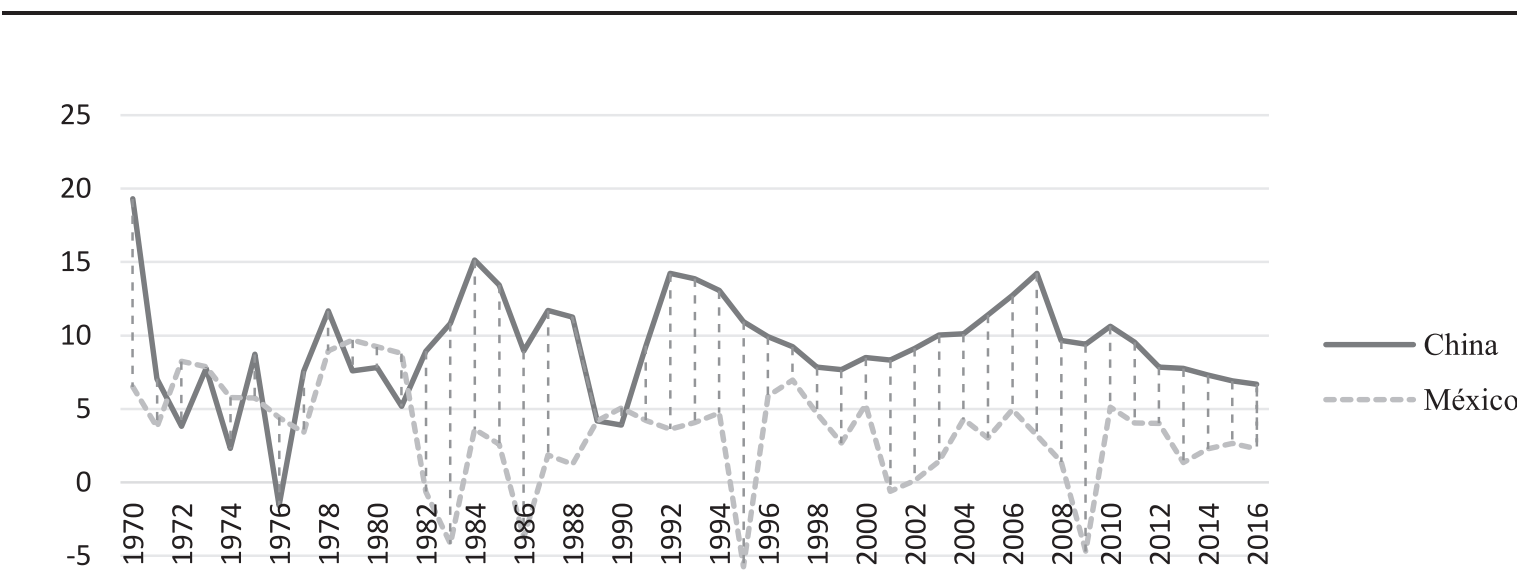

$-10$

Fuente: Elaboración propia con datos de Banco Mundial (2019)

A pesar de que México implementa un esquema de apertura al exterior fundamentado en los mismos objetivos que China, no logró los mismos resultados, al contrario, la tasa de crecimiento del PIB de México, decreció y, al menos del año 2010 en adelante, no supera el 3\%. En la Gráfica 1 se muestra la tasa de crecimiento del PIB para cada economía. Cabe señalar que, para 1988 la tasa de crecimiento del PIB de China era 9 veces mayor que la de México, en 2002 llego a ser cerca de 70 veces mayor y en 2016 casi 3 veces mayor. 
Como se menciona, para la década de 1970, China provenía de una serie de fuertes fracasos económicos y sociales implementados durante el liderazgo de Mao Zedong, como lo fue el programa económico "El Gran Salto Adelante" implementado en 1958 con el objetivo de incrementar la producción de la industria pesada. Dicho programa tuvo un fracaso brutal tal que en el periodo de 1958 a 1962 se estima que 25 millones de chinos murieron de hambre derivado de este programa, puesto que se establecieron objetivos de producción claramente imposibles de alcanzar. Asimismo, China experimentó "La Década Perdida" y, posteriormente, en 1966 Mao impulsó la "Revolución Cultural" que pretendía evitar la restauración del capitalismo a través de reformar la burocracia estatal y el gobierno. Este último programa nuevamente tuvo fuertes repercusiones sociales, además de un estancamiento económico.

Por su parte, México provenía del agotamiento del modelo de sustitución de importaciones implementado durante el periodo de 1945 a 1970. Dicho agotamiento fue marcado por "la crisis de la deuda externa" de 1982, en la que México se vio obligado a declararse en moratoria de su deuda, pues se había quedado sin reservas y no podía pedir más préstamos.

Como se observa en el Cuadro 1, el rezago de México con respecto a China no era tan notorio. En cuanto al crecimiento de la población, en México ha sido mucho más acelerado que el de la economía China, no así su tasa de crecimiento. Lo anterior se puede observar en términos del PIB per cápita, el cual para China en 1978 era de un décimo de el de México, dicha brecha se ha cerrado, siendo una cifra muy similar la que se presenta para ambos países en 2016.

Cuadro 1

Principales variables macroeconómicas

\begin{tabular}{ccccccccc}
\hline Variable & \multicolumn{2}{c}{1978} & \multicolumn{2}{c}{1988} & \multicolumn{2}{c}{2002} & \multicolumn{2}{c}{2016} \\
macroeconómica & China & México & China & México & China & México & China & México \\
\hline $\begin{array}{c}\text { Población (millones) } \\
\begin{array}{c}\text { PIB per cap. (US\$ a } \\
\text { precios actuales) }\end{array}\end{array}$ & 956 & 66 & 1,101 & 82 & 1,280 & 104 & 1,378 & 127 \\
$\begin{array}{c}\text { Crecimiento del PIB (\% } \\
\text { anual) }\end{array}$ & 156.4 & 1552.37 & 283.54 & 2231.18 & 1148.51 & 7106.08 & 8123.18 & 8208.56 \\
$\quad$ & 11.7 & 9 & 11.2 & 1.2 & 9.1 & 0.1 & 6.7 & 2.3 \\
\hline
\end{tabular}

Fuente: Elaboración propia con datos de Banco Mundial (2019)

Tanto México como China, ante la situación económica en la que se encontraban, requerían de un nuevo modelo capaz de regularizar su economía, incentivar la inversión, generar empleo, entre otros intereses sociales. Por ello, a partir de finales de la década de los setenta, ambas economías impulsan una serie de políticas similares, pero con respuestas tanto en el ámbito económico como financiero distinto.

\subsection{Apertura y evolución comercial: asimetrías entre China y México}

Las reformas estructurales implementadas en los países emergentes a partir de finales de la década de 1970 han tenido como resultado un incremento importante en el comercio exterior, en particular de las exportaciones, y crecientes montos de Inversión Extranjera Directa. Sin embargo, es evidente que el vínculo entre el comercio exterior y el crecimiento económico no es necesariamente positivo, ya que dicha relación depende del contexto y las condiciones en las que se haya llevado a cabo la apertura comercial, por lo cual, dependerá de cómo se 
asimilan los cambios internamente, para que el tejido productivo sea potencializado y no destruido. Asimismo, también dependerá del tipo de productos que sean objeto del comercio exterior, para dinamizar los encadenamientos productivos (Vera y Machinea, 2006).

A principios de la década de 1980, países latinoamericanos, incluyendo México, inician una orientación del comercio hacia afuera (externo), es decir, adoptan el modelo de economía abierta. Para el caso mexicano, este estuvo fuertemente sesgado hacia el mercado de Estados Unidos. En 1994 México firma el Tratado de Libre Comercio de América del Norte (TLCAN) y, a partir de entonces, centra su atención en conquistar dichos mercados, dejando de lado su capacidad económica-estructural para llevar la competencia.

En el caso de China, implementó un conjunto de políticas económicas orientadas a lo que se convertiría en su nuevo motor de crecimiento: la apertura externa. Den Xiaoping fijó una serie de políticas estratégicas orientadas a 4 rubros principalmente: la agricultura, industria, defensa y ciencia y tecnología. Con metas establecidas para cada rubro ya mencionado, se establece el "Plan de 10 años"1 donde se establece el crecimiento esperado para cada sector. A diferencia de México, carente de visión estratégica y diferentes criterios partidistas, China inicia su apertura al exterior de manera paulatina, tomando como base planes a mediano y largo plazo, el reconocimiento de sus fortalezas y políticas orientadas a aquellos sectores que requerían atención.

$\mathrm{Al}$ respecto, el sector agrícola ha perdido representatividad como porcentaje del PIB en ambas economías; para el caso de China, en 1978 representaba el $27.7 \%$ y para 2016 dicho porcentaje se reduce hasta 8.6\%; por su parte, para el caso mexicano, pasó de $10.9 \%$ a 3.8\%, en el mismo periodo. Dicha tendencia ha sido compensada por el aumento en la participación económica del sector servicios en ambas economías, el cual, para los mismos años, pasó de 24.6\% a 51.6\% en China, y de 56.3\% a 63\% en México. De hecho, la productividad en China se vio favorecida por una acertada estrategia de movilidad de la población dedicada al sector agrícola a otros sectores.

En la Gráfica 2 se observa la evolución de las exportaciones e importaciones de China y México, para el primer país se observa una evolución con tendencia positiva, hasta el año 2007 cuando se gestó la crisis subprime, a partir de ese año se observa una caída del comercio exterior como porcentaje del PIB; cabe señalar que la balanza comercial es positiva desde el año 2003 (exportaciones >importaciones).

\section{Gráfica 2 Exportaciones e importaciones como \% del PIB (1978-2016)}

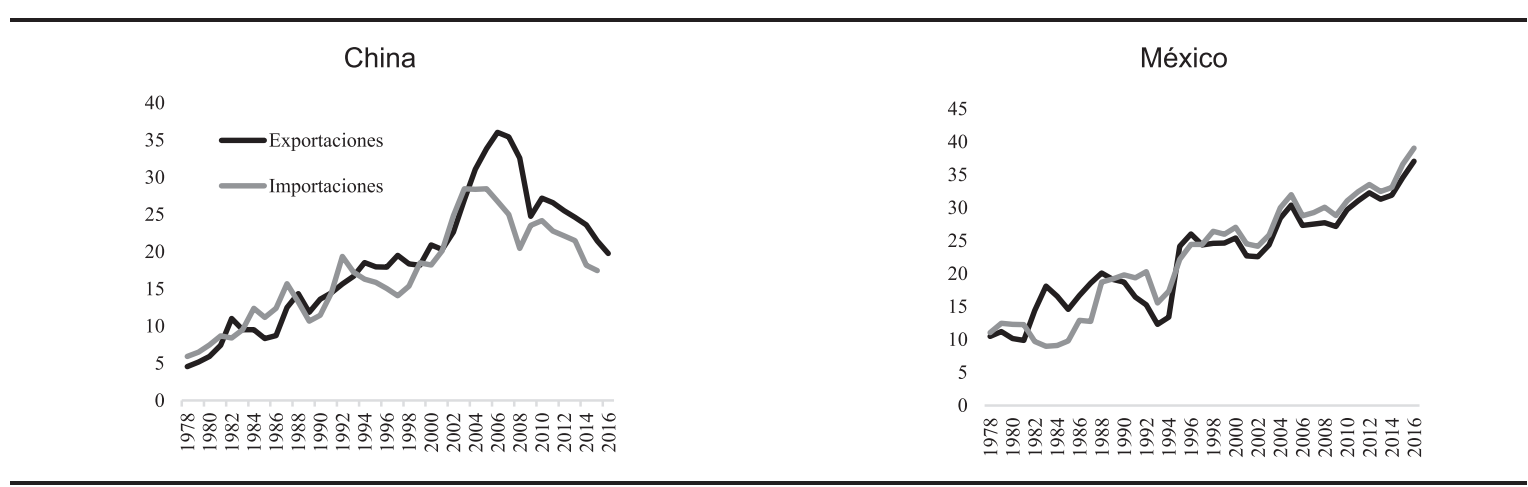

Fuente: Elaboración propia con datos de Banco Mundial (2019)

\footnotetext{
${ }^{1}$ Se enfocaba en la promoción de crecimiento económico a una tasa mayor de $5 \%$ para la agricultura y mayor a $10 \%$ para el sector industrial.
} 
En el caso de México, la tendencia es positiva para todo el periodo, a excepción de la caída presentada por la crisis de 1994; desde 1997 se observa un déficit comercial (importaciones > exportaciones). Si bien, las exportaciones e importaciones como porcentaje del PIB son mayores para México, en términos absolutos (mmd), el total del comercio de México representa tan solo el 8\% del de China. Para el caso mexicano, importar se vuelve una condición. Así, una variable que describe su interacción comercial: la dependencia económica.

Carrada (1996), destaca la diversificación del comercio exterior en los mercados emergentes ya que, ello evita que sufran quebrantos que pudieran originarse en los ingresos por exportación; dicha afirmación exceptúa a México, quien para el año 2016 tenía a EUA como principal socio comercial: 46.5\% del total de sus importaciones proceden de dicho país y $81 \%$ son realizadas hacia dicho país. Para el caso de China, la situación es diferente, los principales socios comerciales de los cuales importa son EUA, Hong Kong y Japón y los países a los que exporta Corea, Japón y EUA, pero ninguno de ellos tiene una representación mayor al 19\% del total de sus exportaciones e importaciones (Observatory of Economic Complexity (OEC), 2016).

Otra cuestión importante es el tipo de productos que son objeto del comercio exterior, al respecto; mientras que, China exporta equipos y componentes electrónicos, especialmente, enfocados a la telefonía y telegrafía e importa materias primas (minerales y aceites crudos); México exporta manufactura automotriz y electrónica y petróleo e importa petroquímica avanzada, componentes electrónicos y partes y accesorios de máquinas. Así, el valor agregado de los productos exportados por China es mucho mayor que aquel de los elaborados en México, lo cual es evidencia del desarrollo industrial de cada país, del capital humano y de los encadenamientos productivos que existen al interior de cada economía, se ahonda al respecto en el análisis de la IED, sección 3.

Como señala Bustelo (1999), al iniciar el proceso de apertura comercial y la globalización, es importante asegurar industrialización, un equilibrio de mercado interno, político y hasta cultural. El nuevo modelo de desarrollo en pro del crecimiento económico debería ser capaz de reestablecer, en principio, el equilibrio macroeconómico.

\section{IED y sector comercial en México y China; un análisis comparativo}

Una vez analizado el periodo de reformas y el proceso de apertura comercial, para cada una de las economías bajo estudio, en el presente apartado se analizan los factores, tanto internos como externos que, con base en Ortiz (2013), afectan la IED. Así, se hace un análisis riguroso de la evolución de cada factor para ambas economías.

La IED, elemento que ha de convertirse en clave para el desarrollo y modernización de los países en desarrollo, figura desde finales de la década de los setenta como el nuevo impulsor de crecimiento que involucra e integra a las economías para generar empleo, desarrollo tecnológico, formación de capital humano, entre otros beneficios que son captados en todos los niveles.

Al tratarse de economías emergentes, los factores que influyen en mayor medida en la IED en China y México son compartidos; sin embargo, ello no necesariamente implica resultados positivos/negativos iguales. Todos estos dependen de la imagen que como nación tienen frente a los inversores extranjeros, de la zona geográfica y del sector productivo (Jiménez, Celina y Aristarco, 2016). En general, estos están relacionados con los costos de producción (salarios), localización geográfica estratégica, infraestructura, y el grado de libertad comercial, es decir, barreras a la entrada de inversión extranjera. 


\subsection{Factores internos que inciden en los flujos de IED: México y China}

De acuerdo con Ortiz (2013), entre los factores que afectan, de manera interna y recurrente la IED, entendiendo por interno aquellas situaciones que pueden ser controladas por el gobierno o sociedad de las naciones, son:

\subsubsection{Reformas políticas}

Con el propósito de generar las condiciones que incentivaran cada vez en mayor medida el interés de los inversores extranjeros, México y China realizaron cambios estructurales y regulatorios que favorecieran la entrada de flujo de capital y asegurar, para el caso de México, lo que sería su nueva fuente para solventar el déficit en cuenta corriente, compensar los bajos niveles de ahorro interno y reducir la tasa de desempleo nacional. Para el caso de China, como una trocha para generar empleos dada la numerosa población, pero también, como medio de financiamiento adicional a la industrialización, desarrollo económico, fuente de divisas y una vía de acceso a tecnología de países desarrollados (Giner y Giner, 2002).

Las reformas en China se caracterizaron por ser graduales y experimentales. Salvador (2012), divide la aplicación de estas reformas en dos etapas: la primera etapa, que transcurre en la década de los ochenta, converge en la Política de Puertas Abiertas, con la que China comienza el proceso de apertura comercial centrada en el fomento a las exportaciones y la modernización tecnológica; y la implantación del Plan Cuatro Modernizaciones, llamado de esta forma por aplicarse a cuatro sectores principales: la agricultura, industria, sector militar, ciencia y tecnología. En la segunda etapa, que da lugar a partir de los noventa, las reformas se focalizan a crear instituciones y un marco legal y regulatorio que cumpla y sea compatible con el desarrollo actual de su economía.

Por su parte, México también comienza a incorporarse a un mundo cada vez más globalizado a finales de los setenta y con mayor fuerza a principios de los ochenta. Hasta antes de su liberalización, en México gobernaba y valoraba la estrategia de desarrollo "hacia dentro", la industrialización sustitutiva de importaciones (ISI), los elevados controles arancelarios y la notoria intervención del Estado, todo ello bajo un marco referencial de desarrollo socioeconómico del mercado interno. Este esquema, cuyo sector y principal fuente de financiamiento era el agrícola, proliferó por años hasta que fue evidente su ineficiencia (déficit comercial y fiscal, inflación de $160 \%$, disminución del PIB, etc.) en un entorno globalizado que ejercía cada vez mayor presión sobre las economías cerradas, entre ellas México.

Dado este contexto, México implementó nuevos esquemas regulatorios, iniciando con su adhesión al Acuerdo General sobre Aranceles y Comercio (GATT) en 1986, con el que rápidamente se restableció un nuevo esquema arancelario en el que se eliminó por completo el programa de sustitución de permisos previos a exportación e importación (Dussel, Galindo, Loría y Mortimore, 2007); y al Pacto de Solidaridad Económica (PSE) en 1987, el consecuentemente establecimiento del control de variables prioritarias para el sistema económico como la inflación y el déficit fiscal, la reestructuración de medidas arancelarias, la privatización de empresas estatales y la negociación del TLCAN en 1994.

México en particular, y los países periféricos en general deben, de acuerdo con Garay (2012), el notorio impulso de la IED a la promoción por parte del Fondo Monetario Internacional y el Banco Mundial a través de la aplicación de medidas propugnadas por el Consenso de Washington: privatizaciones, liberalización comercial y financiera, etc. 
Durante este periodo, no únicamente se presentaron cambios cuantitativos, sino también de carácter cualitativo: el surgimiento de operaciones outward procedente de empresas de países en desarrollo y las Fusiones y Adquisiciones Transfronterizas (FyATs) ${ }^{2}$ Galaso, Olivas y Sánchez (2016). Las FyATs en México estuvieron favorecidas por las nuevas condiciones de competencia orientadas a la desregulación y apertura comercial, la reestructuración de leyes relativas a la recepción de IED, la privatización de empresas públicas y el inicio de importantes tratados comerciales implementados desde la administración de 1983, con Miguel de la Madrid, y especialmente en los noventa; pero también al desempeño económico con rasgos positivos.

Las FyATs inward horizontales son mayoritarias en México, lo que advierte la concentración de mercados. Como efecto adverso a este esquema se encuentra el cambio en las condiciones de oferta; la tecnología y el acceso a mercados puede generar producción a escala que puede provocar concentración económica y mayor poder de mercado por las empresas compradoras, desfavoreciendo el mercado interno. En México, esta modalidad sugiere una elevada concentración; en 2-3 operaciones inward se puede explicar más de 80\% del capital total. Garrido (2001), señala que esto significa que ha habido muchas operaciones de venta de empresas a favor de empresas extranjeras. De hecho, esto se hace más notorio al analizar el rango de capital adquirido en las FyATs inward por porcentaje de operación y monto (Ver Cuadro 2).

El 45\% de las operaciones de FyATs inward representaron el 53.8\% del monto total, lo cual sugiere que la mayor parte de las empresas extranjeras muestran un importante interés por adquirir un mayor control y derechos de propiedad de las empresas nacionales frente, por ejemplo, en las que fungirían como socios minoritarios (0-10\%), que únicamente representó el 1.7\% del monto total.

Cuadro 2

Estrategias de inversión Inward, 1990 - 2000

\begin{tabular}{ccc}
\hline $\begin{array}{c}\text { Rango del capital } \\
\text { adquirido en la FyATs } \\
\text { (en porcentajes) }\end{array}$ & $\begin{array}{c}\text { Inward (100 mayores operaciones) } \\
\text { Porcentaje del } \\
\text { monto total }\end{array}$ \\
\hline o a 10 & 6 & 1.7 \\
11 a 49 & 27 & 26.5 \\
50 a 100 & 45 & 53.8 \\
No identificado & 22 & 18.1 \\
\hline
\end{tabular}

Fuente: Garrido, C. (2001) "Fusiones y adquisiciones transfronterizas en México durante los años noventa", México, Cuadro 7, datos seleccionados.

\subsubsection{Localización}

A este aspecto, señala Salas (2006), corresponden las ventajas como los recursos naturales, materias primas, fuentes de abastecimiento, infraestructuras modernas, etc. Para el caso de China, destaca la creación de las zonas especiales (o abiertas) cuya creación geográfica, sectorial y por modalidad de inversión también se dio de

\footnotetext{
${ }^{2}$ Las FyATs pueden ser de dos tipos: outward o inward. Las primeras dan lugar cuando una empresa nacional compra empresas ubicadas en el exterior, mientras que las segundas, se trata de lo contrario, empresas ubicadas en el exterior realizan la compra de una empresa nacional (Garrido, 2001). Para efectos del presente, se analiza las FyATs de tipo inward.
} 
forma gradual; es decir, se implantaron zonas económicas especiales y con la experiencia de las primeras se abrieron otras cuyas características u objetivos se definieron de acuerdo a la naturaleza o actividad comercial que se buscaba para atraer IED.

En 1979, China inicia este proceso de liberalización con la creación del Parque Industrial de Shekou, un área manufacturera, comercial y residencial concentradora de empresas extranjeras (Mena, 2011). Posteriormente, se crearon las primeras cuatro Zonas Económicas Especiales (ZEE): Zhuhai, Shenzen, Shantou y Xiamen (Salvador, 2012). Donde, como se mencionó, además de atraer IED, sirvieron al gobierno chino para evaluar su desempeño y crear otras zonas especiales en el territorio del país, especialmente, en la zona costera (zona sur).

En estas zonas, el gobierno ofrecía estímulos fiscales a la importación de productos, reducción de tasas de impuestos, exención de impuestos a bienes producidos en ellas y facilidades en los procedimientos aduaneros, todas estas orientadas en mayor medida a la exportación.

En 1984, China inicia una segunda etapa y con ella una mayor profundidad de reformas, cuya base estuvo en función de la experiencia adquirida con la creación, desarrollo y resultados de las ZEE previamente creadas. Bajo un marco regulatorio muy similar al que manejó en estas zonas, China crea catorce Ciudades Costeras Abiertas ${ }^{3}$, las Zonas de Desarrollo Económico y Tecnológico (Economic and Tecnology Development Zones), la isla de Hainán (en 1987), la Zona de Desarrollo de Pudong en Shanghai (en 1990).

Es hasta inicios de los años noventa que se inicia la tercera etapa de este proceso de liberalización gradual y experimental que se crean las zonas especiales, esta vez con la creación de las Zonas de Alto Desarrollo Tecnológico HTDZs (High Technology Development Zones), cuyo objetivo se centró en la atracción de IED ya no para la exportación sino para la adquisición de tecnología; y las dos primeras Áreas de Libre Comercio (Free Trade Areas); sin embargo, con la creación de estas zonas también trajo disparidades regionales promoviendo flujos migratorios y desempleo urbano (Wang, 2013 y Qu y Green, 2018).

Como se observa en la Gráfica 3, las regiones Jiangsu, Guangdong, Shandons y Zhejiang concentran más de $50 \%$ de la IED; en contraste, "otros", que incluye 21 regiones y representan el 26.66\% de la IED total.

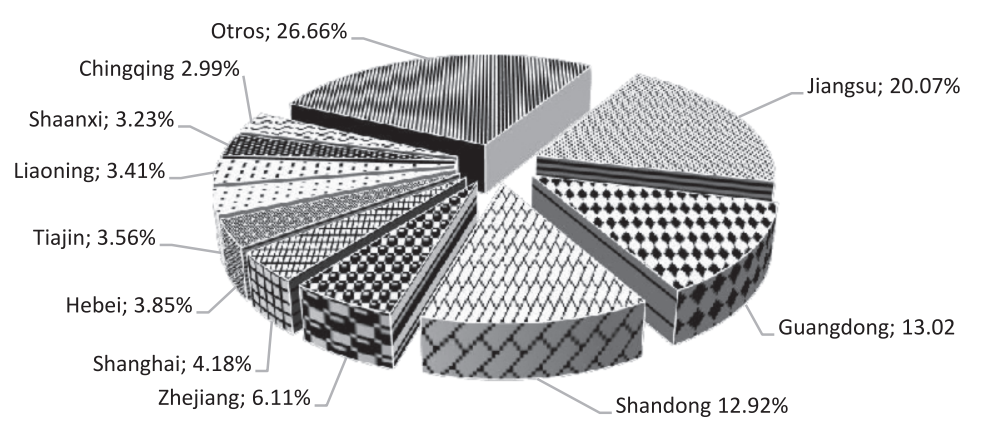

Fuente: Elaboración propia National Bureau of Statistics of China, China Statistical Yearbook.

${ }^{3}$ Dalian, Qinhuandao, Tianjin, Yantai, Qingdao, Lianyuguang, Nantong, Shanghai, Ningbo, Wenzhou, Fuzhou, Guangzhoy, Zhanjiang y Beihai. 
Por su parte, en México la infraestructura también ha sido un factor determinante en la atracción de IED (Mollick et al, 2006). Ortega (2015), concluye que durante el periodo 1999-2013, la IED que ingresó a México pareció determinarse con base en tres factores: regiones con mayor demanda económica, mayor desarrollo de infraestructura y localización geográfica estratégica. Mollick et al (2006), pone de ejemplo a los Estados de Querétaro y Puebla posterior a la construcción de infraestructura aeroportuaria.

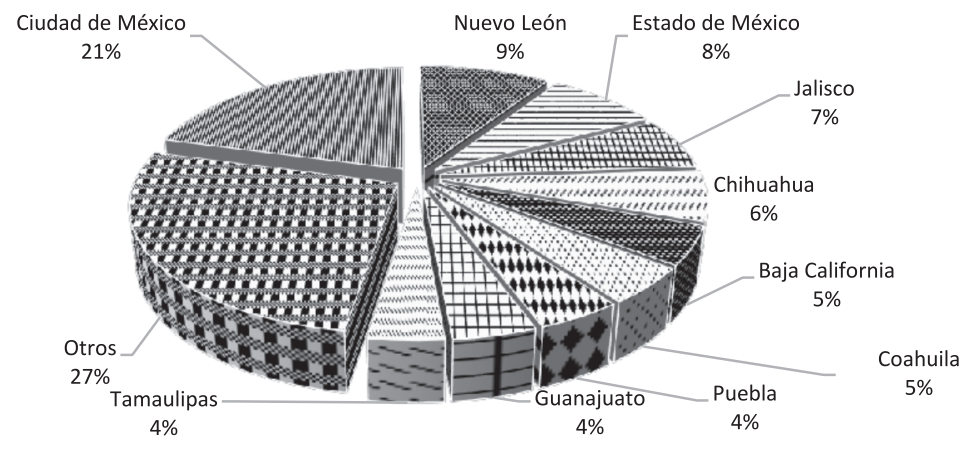

Fuente: Elaboración propia. Secretaría de Economía.

Como se observa en la Gráfica 4, la capital del país es la principal zona de atracción de IED, por la gran concentración de infraestructura, población, comercio, entre otros factores que generan un efecto "aglomeración" con externalidades positivas en dicha zona. Asimismo, la mayoría de los Estados con mayor representatividad como receptores de IED se localizan en la zona Norte y colindan con la frontera de EU: Nuevo León, 9\%; Chihuahua, 6\%; Baja California, 5\%; Coahuila, 5\%; Tamaulipas, 4\%; y Sonora, 1.7\%. En términos generales, esto se atribuye a la cercanía con el principal socio comercial y los costos de transporte más bajos. Asimismo, destaca el Estado de Jalisco que mantiene importantes lazos comerciales con EU.

\subsubsection{Marco institucional, legal yjurídico}

Con su política Open doors y su posterior entrada a la OMC en 2001, China marca de manera histórica un parteaguas a la ortodoxia conservadora y aislada a la que estaba acostumbrada, a ser una economía innovadora. Su impacto ha sido tal que, autores como Roa (2012) consideran ésta como la forma más importante por la que China se enlista como el mayor receptor de IED entre los países en vías de desarrollo. En contraste con la concepción de Bustelo (2004), quien considera que dicha incorporación, a largo plazo, es perjudicial para sectores como la agricultura y automotriz.

Adicionalmente, China adopta una nueva legislación sobre la IED en 1994 (Ley de Sociedades china), en la que establece las diversas modalidades de proyectos de inversión extranjera y tipología de proyectos de inversión (Giner y Giner, 2002), las más frecuentes son: Ley de Oficinas de Representación (Representative Offices), Ley de Sucursales (Branch Offices), Ley de Empresas mixtas (Joint Ventures), Ley de Empresas totalmente extranjeras (Wholly Foreign Owned Enterprises), y Ley de Sociedades Holding. Igualmente, con el 
fin de llevar un mayor control de las Wholly Foreign Owned Enterprises (WFOEs, empresas de capital totalmente extranjero), se dividen los proyectos en: favorecidos, restringidos, prohibidos, de participación totalmente extranjera y bajo control del Gobierno.

La orientación de las WFOEs se realiza en función de la convergencia de dichos proyectos con los intereses nacionales. A reserva, de la gradual disminución de limitantes a este tipo de inversiones que China se ha comprometido a suprimir a su ingreso a la OMC. De hecho, como representatividad por tipo de proyecto, las WFOEs han pasado de representar $59.84 \%$ en 2001, a $75.35 \%$ en 2016; en contrapartida con las modalidades Equility Joint Venture y Contractual Joint Venture, que pasan de $34.02 \%$ a $23.88 \%$ y $6.08 \%$ a $0.45 \%$, respectivamente (Ver Cuadro 3).

Cuadro 3

\begin{tabular}{lcccccc}
\hline & 2001 & 2004 & 2007 & 2010 & 2013 & 2016 \\
\hline Equity Joint Venture & $34.02 \%$ & $26.50 \%$ & $20.20 \%$ & $18.13 \%$ & $19.65 \%$ & $23.88 \%$ \\
$\begin{array}{l}\text { Contractual Joint Venture } \\
\text { Wholly Foreign-owned }\end{array}$ & $6.08 \%$ & $3.08 \%$ & $1.69 \%$ & $1.09 \%$ & $0.62 \%$ & $0.45 \%$ \\
Enterprise & $59.84 \%$ & $70.33 \%$ & $78.01 \%$ & $80.58 \%$ & $79.59 \%$ & $75.35 \%$ \\
Otras & $0.06 \%$ & $0.10 \%$ & $0.10 \%$ & $0.19 \%$ & $0.13 \%$ & $0.31 \%$ \\
\hline
\end{tabular}

Fuente: National Bureau of Statistics of China, China Statistical Yearbook, varios años.

Giner y Giner (2002), enlistan algunos de los incentivos fiscales más importantes; a grandes rasgos, estos se centran en la reducción de gravamen a empresas exportadoras dedicadas a actividades relacionadas con tecnología avanzada; la reducción de impuestos sobre la renta para empresas de tecnología avanzada y empresas productivas con inversiones a más de 10 años; y exención de aranceles de aduanas e impuestos que correspondan a la importación de bienes de equipo, piezas, bienes de capital, materia prima, etc. en calidad de componentes necesarios o beneficio a la inversión de exportación. Sin embargo, de acuerdo con el nuevo Catálogo, en el que China expresa su política económica global, la nueva orientación y principal objetivo de la inversión extranjera es reforzar las industrias de alta tecnología, investigación y desarrollo, la fabricación de gama alta, sectores ecológicos y nuevas energías (Salvador, 2012).

Por su parte, México tiene la Ley para Promover la Inversión Mexicana y Regular la Inversión Extranjera (DOF, 1973), México tuteló la normatividad de la IED hasta 1993 (Dussel, Galindo y Loría, 2003), año en que reestructuró dicha Ley. En esta nueva Ley, se elimina el límite de inversión externa como proporción de las sociedades mexicanas y los requisitos de desempeño que la Ley de 1973 abarcaba. Sin embargo, prevalecen algunas actividades en las que dicha porción de inversión extranjera sobre las sociedades mexicanas es limitada, especialmente la relacionadas con petróleo e hidrocarburos, petroquímica básica y electricidad. 


\subsubsection{Tamaño de mercado}

Éste factor puede ser estudiado a través de dos guías: el tamaño de población, visto como la magnitud de consumidores en un país; y el ritmo de crecimiento, generalmente medido a través del PIB.

En definitiva, es reconocido el tamaño poblacional de China, y por ende éste parece ser un factor evidente; en 1978, año en que se da a la apertura comercial, la población china era catorce veces mayor que la mexicana; en 2016, es once veces mayor. Sin embargo, cabe destacar que no es un factor cuya relación sea condicionalmente positiva en la atracción de IED o el crecimiento del PIB.

Por consiguiente, diversos estudios como el de Ortega (2015), Bittencourt y Domungo (1996 y 2004), Mogrojevo (2005), entre otros, confirman la existencia de una relación positiva entre PIB y el nivel del flujo de IED en una economía. El desempeño económico medido a través de este indicador refleja un ambiente de negocio estable y certero al que los inversores extranjeros se verán atraídos; Galoso, Olivas y Sánchez (2016), menciona que el indicador que refleja el poder de compra del mercado interno es el PIB per cápita. A este respecto, a 2016, el PIB de China representa el 12.25\% del PIB mundial, superando por 7 veces la relevancia de la economía mexicana.

A pesar de que no es directo el vínculo entre IED y PIB, para el caso de México y China, la IED parece replicar la tendencia del PIB del país respectivo. De acuerdo con Zebregs (2003), la IED ha contribuido al crecimiento económico (PIB), a la productividad del trabajo, a la creación de oportunidades de empleo y a la Formación Bruta de Capital (Salvador, 2012 y Labrador, 2006).

\subsubsection{Diferencial de salarios}

De acuerdo con Ortega (2015), la importancia del diferencial de salarios es evaluada de acuerdo al país receptor de IED, es decir, si es un país desarrollado, el mayor interés es aprovechar el tamaño de mercado y/o la demanda interna; pero, si por el contrario es un país subdesarrollado, el mayor interés se resume en la búsqueda por disminuir los costos de producción: salarios bajos. Así, el diferencial de salarios funge como indicador de costos de producción, mayor margen de ganancias o un rendimiento más alto.

Al respecto, existe vasta información que hace referencia a este indicador, especialmente para el caso de China. Todas estas parecen señalar que los bajos salarios en China les permitieron posicionarse como un reconocido competidor a nivel mundial en el sector manufacturero (producción de partes y componentes). En un inicio del proceso de apertura, se generaron problemas por la falta de mano de obra calificada; sin embargo, fue contrarrestado con inversión en educación (Salvador, 2012 y Labrador, 2006).

En México también es un hecho la reducción de los costos laborales como factor determinante de un mayor flujo de IED. EU ha presentado interés en el desarrollo de sectores relacionados con la modernización tecnológica, la exportación y servicios de alta productividad (Dussel, Galindo, Loría y Mortimore, 2007).

Como se aprecia en la Gráfica 5, en 2009 el salario mínimo de estos países cruza a un nivel similar (84.3 $€$ en China y $84.1 €$ en México), desde entonces la tendencia ascendente China ha dejado considerablemente atrás el mínimo en México, lo que advierte una "ventaja" frente a China. De hecho, la tendencia de la IED en México parece reproducir la del salario mínimo; de 2003 a 2007 la tendencia de la IED fue contraria a la tendencia del salario mínimo, es hasta 2008 que la tendencia del salario mínimo se reproduce en el flujo de IED. 


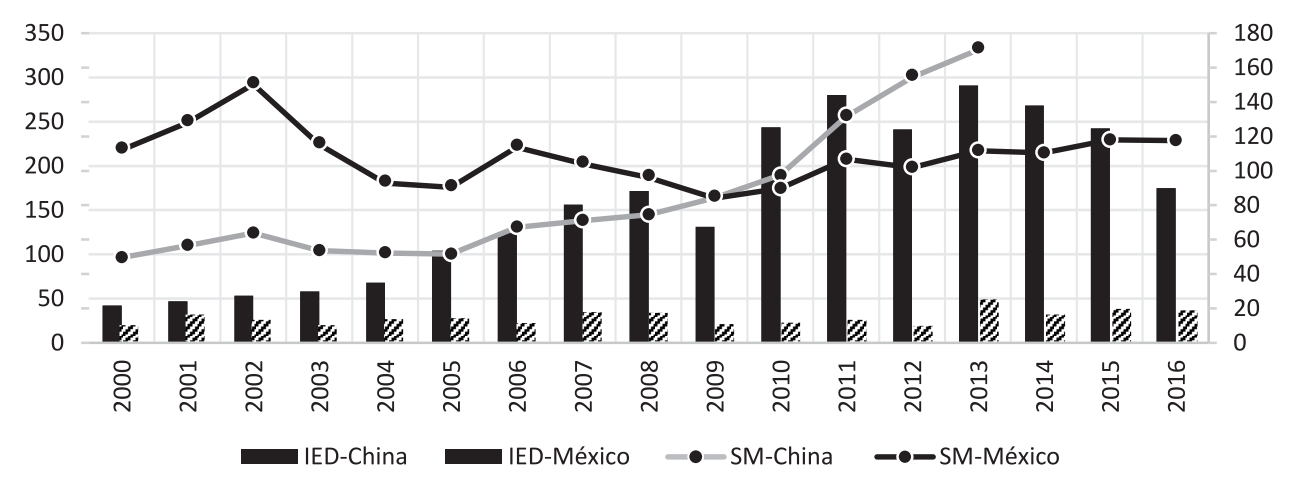

Fuente: Elaboración propia con datos de Expansión-Datos macro.com y Banco Mundial.

En China, por su parte, a excepción de periodos cortos (2003-2005, 2008-2009, 2011-2012) la IED rehace la tendencia del salario mínimo. Se puede considerar, relativamente hablando, que el bajo salario en China, que incluso en 2000 era menos de la mitad del salario mínimo en México, fungió como uno de los más importantes factores para posicionarle como competidor a nivel mundial en la industria manufacturera; sin embargo, recientemente la IED en China está ligado en mayor grado a factores como localización geográfica y estratégica, mano de obra abundante y un entorno macroeconómico con rasgos positivos, como la inflación, tipo de cambio, etc. Lo que se hace más evidente al ver la tendencia del salario mínimo que recorre desde 2006, siempre positiva.

\subsubsection{Evolución y composición de las exportaciones}

Como se ha mencionado, la política comercial aperturista trajo consigo un incremento de las exportaciones en ambas economías. Sin embargo, a pesar del notorio incremento de las exportaciones manufactureras ${ }^{4}$ en México, después de alcanzar su punto más alto de superávit en 1982, presenta déficit comercial cuya persistencia inicia en 1989. En 1985, el déficit encuentra su punto más bajo al importar más de 60\% de lo que exportó en ese año (Banco Mundial, 2019).

China, por su parte, mantiene un superávit, con excepción de periodos cortos (1984-1986 y 1988-89 y 1993). A 2016, México importa 5.2\% más de lo que exporta, manteniendo con ello un déficit comercial. Por su parte, China exporta $13.17 \%$ más de lo que importa, exponiendo con ello, un superávit comercial. Como se observa en el Cuadro 5, en China y México domina la exportación de máquinas y equipos tecnológicos (48\% y $37 \%$, respectivamente) que incluyen equipos de cómputo, equipos de radiodifusión, teléfonos, entre otros cuyo valor agregado ${ }^{5}$ es mayor . China supera en $11 \%$ el nivel de exportaciones de México al mundo, lo que resalta de primer momento un diferencial evidente (Banco Mundial, 2019).

\footnotetext{
${ }^{4}$ La tasa de crecimiento de las exportaciones de 1982 a 2016 ha sido de $1421 \%$ para México, y de $9199 \%$ en China para el mismo periodo.

${ }^{5}$ De acuerdo con un artículo publicado por Scheel y Pineda (2015), los productos con mayor valor agregado se identifican por el grado de innovación y tecnología que ofrecen.
} 
En general, de acuerdo con datos del Banco Mundial (2019), el valor agregado de la industrialización como porcentaje del PIB en China es significativamente mayor que en México; considerando que con 25\% de representatividad, el segundo sector que más figura en las exportaciones de México es el de transporte, el cual incluye carros, partes de carros, motocicletas, etc., queda aún una brecha importante entre dichos países.

Adicionalmente, a pesar de su representatividad como exportador de máquinas y equipos tecnológicos y de su popularidad en la industria de transporte, México no ha logrado pasar de ser un proveedor y ensamblador de automóviles, equipo de cómputo, comunicación, etc., a posicionar alguna marca propia a nivel mundial en dicho sector. México continúa especializándose en sectores tradicionales y servicios con marcas como Cinépolis, Televisa, Telcel y Maseca, por mencionar algunos. En contrapartida, Xiaomi, Huawei, Hisense, Cheeta Mobile, Anker, Haier, Air China, Lenovo, entre otras, son algunas de las marcas chinas que figuran como las más competidas en la industria tecnológica a nivel mundial.

Cuadro 4

Sectores más representativos sobre exportaciones totales, 2016

\begin{tabular}{llll}
\hline & China & México \\
\hline Manufactura & $48 \%$ & Manufactura & $37 \%$ \\
Textiles & $10 \%$ & Transportación & $25 \%$ \\
Metales & $7.3 \%$ & Productos Minerales & $5.9 \%$ \\
Diversos & $6.6 \%$ & Instrumentos & $5.1 \%$ \\
Productos químicos & $4.7 \%$ & Productos Vegetales & $4 \%$ \\
\hline
\end{tabular}

Fuente: The Observatory of Economic Complexity (OEC).

\subsection{Factores externos que inciden en el flujo de IED: México y China}

\subsubsection{Crisis económicas}

De acuerdo con Poulsen y Hufbauer (2013), la entrada de IED a China parece ser poco sensible a los cambios de situación de los principales países emisores a nivel mundial, los desarrollados. Sin embargo, la evidencia empírica muestra un diagnostico muy distinto para México. El flujo de IED en esta nación responde a los acontecimientos internacionales, especialmente al dinamismo económico de sus principales socios comerciales Estados Unidos, España y, en menor medida, Alemania.

Al identificar la IED como factor positivo en el crecimiento económico se debe prestar atención a la concentración y dependencia, por país de origen de la IED (Garriga, 2017). Con base en la Gráfica 6, se hace evidente el vulnerable estado de la economía mexicana al revelar el grado de concentración/representatividad de la IED proveniente de EU en el 49\%, de 1999 a 2016 (Ver Gráfica 6). 


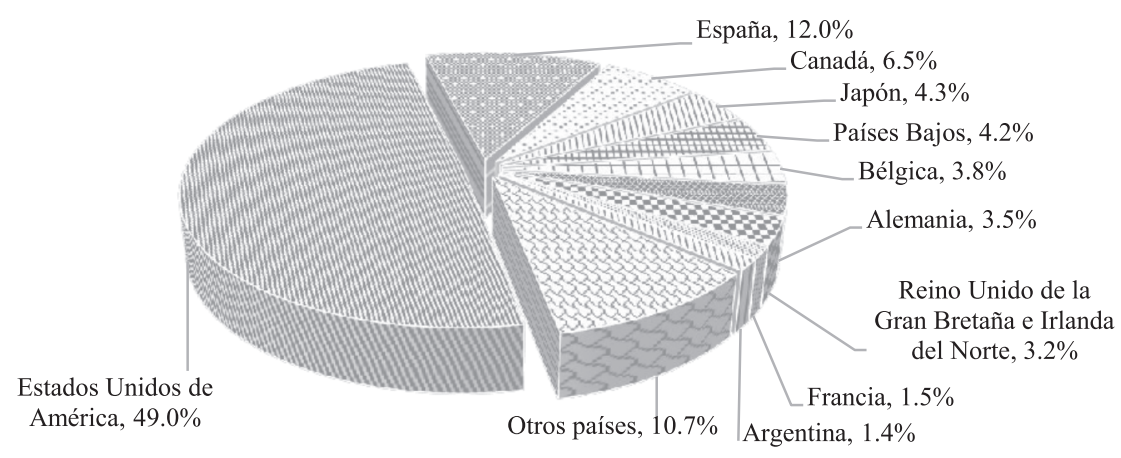

Fuente: Elaboración propia con datos de Banco Mundial (2019)

Por su parte, de acuerdo con un artículo publicado por la British Broadcasting Corporation (BBC) en 2014, los diez países que en orden de significancia invierten en China son: Hong Kong, Taiwán, Singapur, Corea del Sur, Japón, Estados Unidos, Alemania, Reino Unido, Francia, y Holanda. No obstante, el grado de concentración de IED en 2016 parece, por mucho, mayor en China que en México (Ver Cuadro 6); lo anterior contradice a la literatura revisada, respecto a los efectos negativos de la concentración de las fuentes de origen de la IED. Así, China presenta una alta dependencia respecto de Hong Kong quien, así como México, aprovecha de la cercanía y los bajos costos de transporte China, además, toma ventaja de elementos adicionales como: cultura eidioma.

\begin{tabular}{lcll}
\hline & China & & México \\
\hline Hong Kong & $69 \%$ & Estados Unidos & $36.76 \%$ \\
Singapur & $5 \%$ & España & $9.98 \%$ \\
Corea del Sur & $4 \%$ & Alemania & $8.90 \%$ \\
Estados Unidos & $3 \%$ & Canadá & $7.49 \%$ \\
Macao & $3 \%$ & Israel & $6.71 \%$ \\
\hline
\end{tabular}

Fuente: The Observatory of Economic Complexity (OEC). 


\subsubsection{Integración regional}

De acuerdo con Giner y Giner (2002), el número de acuerdos firmados por China con otras economías, cuyo fin se centra en la atracción de flujos de IED, tiene una importante evolución; para el periodo de 1978-80, existían un total de 16 acuerdos firmados y para 1997 se habían formalizado un total de 181 acuerdos.

Por su parte, a raíz de la apertura comercial, México ha concretado diversos acuerdos internacionales que facilitan la entrada de capitales extranjeros a territorio nacional, así como garantías adicionales a la IED. De acuerdo con Garriga (2017), a 2014 se habrían firmado un total de 29 acuerdos bilaterales de inversión.

Además, hace referencia Dussel, Galindo y Loría (2007) a raíz de la firma del TLCAN, el gobierno mexicano concreto un número considerable de Acuerdos para la Promoción y la Protección Recíproca de las Inversiones (APPRI), especialmente para brindar seguridad a los acuerdos bilaterales de inversión; de acuerdo con estos autores, a 2002, se habían firmado más de 12 APPRI incluyendo a Cuba, Nicaragua, Bolivia, Israel, Chile y Suiza.

De acuerdo con datos más recientes, ambos países han concretado un importante número de acuerdos arancelarios anualmente; en 2014, México habría concretado un total de 47 acuerdos, mientras China 30; en 2015 China concretó un total de 22 acuerdos, mientras que México 1 (Panagariya, 2013 y de Lucio, 2019).

\subsubsection{Desconocimiento de mercados}

$\mathrm{Al}$ respecto, se puede hacer referencia a lo que se conoce como obstáculos ideológicos, la distancia psicológica, corrupción y aspectos culturales y de aglomeración, cuyo impacto se refleja en la credibilidad y transparencia que China y México reflejen al resto de los países inversores.

De acuerdo con Ren et al (2014), aún previo a la adhesión de China a la OMC en 2001, los flujos de IED en China ya presentaban un crecimiento bastante considerable. De acuerdo con esta autora, esto se debió al viaje de Deng Xiaoping al sur de China en la primavera de 1992, en la que después de los sucesos de Tiananmen, logró eliminar la incertidumbre respecto al planteamiento de política comercial en China.

La aglomeración se refiere a aquellas externalidades positivas de la IED, de las que autores como Aiken, Hanson y Harrison (1997) y Ortega (2015) ya han hecho referencia. Otro de los factores que favorece la entrada de IED se encuentra el PIB, como principal indicador de estabilidad económica, genera expectativas favorables a la inversión. El tamaño de mercado es otro de los factores de aglomeración; Ortega (2015), señala que, para el caso de México, existe un evidente efecto de aglomeración en la capital del país debido a la gran concentración de capital, poblacional, económica y política existente en esta respecto del resto de los Estados.

Cheng y Kwan (2000) y Head y Ries (2004), estudian la aglomeración como determinantes de los flujos de IED específicamente en China. De acuerdo con los autores mencionados, la localización de la industria es un factor de aglomeración significativo en la entrada de IED en China, ello puesto que, una vez atraída una masa considerable de IED en cierta zona, lo que percibirán otros inversores será un ambiente con posibilidades de intercambio de tecnología, experiencia, etc.

Asimismo, de acuerdo con Ortega (2015), la inestabilidad, la inseguridad social o el cambio de poder en el gobierno federal y estatal en México parecen ser un factores poco relevantes para los inversionistas extranjeros, ello puesto que el gobierno mexicano, a través de diversas políticas públicas, protege la IED, además de la ausencia de expectativas relacionadas con cambios en la política económica del país que pudiera afectar el nivel comercial en el que se desarrollan, independientemente, incluso de la alternancia del poder entre partidos. 
Respecto al tema de corrupción, Egger y Winner (2005) y Mathur y Sing (2013) señalan que es un factor cuyo efecto es casi nulo en la atracción de IED. De acuerdo con este autor, México y China se perciben como economías de un alto nivel de corrupción. Sin embargo, de acuerdo con el puntaje del Índice de Percepción de Corrupción (IPC) ${ }^{6}$, a pesar de tener un margen de diferencia bastante reducido (de 2002 a 2016 el IPC de ambos países ha oscilado en un rango de 3 a 4 puntos), la percepción del grado de corrupción favorece a China.

En cuanto a los aspectos culturales y distancia psicológica ${ }^{7}$, la economía China parece presentar mayores dificultades que México, especialmente por el idioma. De hecho, a este aspecto Du, Harrison y Jefferson (2012) parece encontrar la condición por la que los principales flujos de IED proceden de países como Hong Kong, Singapur y Taiwán: rasgos culturales.

\section{Reflexiones y comentarios finales}

Del análisis previamente desplegado, queda evidenciado que los procesos de apertura comercial y las reformas económicas liberalizadoras que condujeron la economía china y mexicana tuvieron un claro diferenciador; mientras China lo llevo a cabo a partir de un plan estratégico de largo plazo implementado gradualmente, México fue respondiendo de forma reactiva e irrestricta ante los estímulos del exterior, teniendo como punto de partida la crisis que prosiguió al boom petrolero.

El resultado ha sido, por un lado, una potencia emergente con un aparato industrial robusto que compite con economías avanzadas, que presenta crecimiento económico superior a los demás países, que ha elevado el nivel de bienestar de su población y que tiene capacidad de reacción ante choques externos y liderazgo regional y; por otro lado, una economía "emergente" basada en la exportación de manufactura y bienes primarios, con tasas de crecimiento muy modestas, con gran porcentaje de su población en pobreza, que carece de estrategias para la reacción ante eventos externos, lo que la hace vulnerable, y que es dependiente de su principal socio comercial.

En términos de la política económica, México carece de visión a largo plazo y está limitado a paliar distorsiones macroeconómicas a corto plazo. En su búsqueda por preservar la estabilidad de precios, cuyo resultado tampoco ha sido exitoso, el crecimiento económico, pleno empleo, la distribución más equitativa del ingreso y riqueza y el equilibrio de la balanza de pagos que México ha tratado de resolver desde la apertura comercial, han tenido un desempeño marginal.

En cuanto a la IED, en México la entrada de inversión extranjera tomó forma de operaciones outward y FyATs inward horizontales. En principio, todas estas estuvieron favorecidas por las condiciones de desregulación y el inicio de importantes tratados comerciales, desde el periodo presidencial de Miguel de la Madrid, por la privatización de empresas públicas en los noventa, lo anterior trajo como resultado un alto grado concentración en diversos mercados.

En tanto que, en China las empresas de capital extranjero están categorizados por tipo de proyectos; a pesar de que, las WFOEs es la modalidad de inversión más empleada, están controlados y limitados por el gobierno chino, éste les da libertades de acuerdo a las necesidades e intereses nacionales.

\footnotetext{
${ }^{6}$ El Índice de Percepción de Corrupción (IPC) se refiere a la percepción del grado de corrupción visto por empresarios y analistas de riesgo, y se extiende entre 10 (altamente limpio) y 0 puntos (altamente corrupto).

${ }^{7}$ Entendida como las diferencias entre distintos países en términos de lenguaje, cultura, sistema económico, político, prácticas comerciales, etc., variables que obstaculizan la comunicación de las empresas con los distintos países y sus mercados" (Avendaño y García, 2013).
} 
En cuanto a las lecciones y reflexiones que se desprenden del presente, queda reconocer que, tanto el contexto económico y financiero internacional, como las relaciones que cada economía guarda con el exterior, son totalmente distintas en la actualidad, con respecto a las de hace casi cuatro décadas, por lo que, las acciones y estrategias económicas que pudiera emprender México deben ser evaluadas desde el escenario actual.

Es importante buscar mecanismos de fortalecimiento industrial y generación de capital humano que permitan promover la innovación y desarrollo tecnológicos, fortaleciendo a las ya existentes empresas y buscando generar nuevas firmas mexicanas, aliviando las dependencias con el exterior. Lo anterior, con base en una estrategia política de largo plazo, en la que se establezcan prioridades de orden nacional y se cumplan, independientemente, del partido político que se encuentre en el poder. Así, se podrá dirigir la IED y el comercio exterior a las necesidades de dicha industria, aprovechando ambos factores como potencializadores del crecimiento y no, como a la fecha, como mecanismos de dependencia hacia el extranjero.

Si bien la evolución del comercio e Inversión Extranjera Directa es un factor clave para explicar el desempeño económico y la disparidad del mismo entre las economías china y mexicana, existen otras variables a considerar, tales como el sector financiero y aspectos históricos y culturales, por lo que, dichos factores podrían ser objeto central de investigaciones ulteriores.

\section{Referencias}

Aitken, B., Hanson, G. H., \& Harrison, A. E. (1997). Spillovers, foreign investment, and export behavior. Journal of International economics, 43(1-2), 103-132.

Avendaño, E., and Garcia, M. (2013). Rendición de Cuentas y Combate a la Corrupción: Retos y Desafíos. Secretaria De La Función Pública, (6), 31-50. Retrieved November 3, 2015, from https://www.mexico evalua.org/wp-content/uploads/2013/03/cuaderno-06.pdf

Banco Mundial (2019), Indicadores de Desarrollo Económico https://databank.worldbank.org/source/worlddevelopment-indicators

Bittencourt, G., \& Domingo, R. (1996). Inversión extranjera directa en América Latina: tendencias y determinantes. Documento de Trabajo/FCS-DE; 6/96.

Bittencourt, G., \& Domingo, R. (2004). Efectos de "derrame" de las empresas transnacionales en la industria manufacturera uruguaya (1990-2000). Documento de Trabajo/FCS-DE; $12 / 04$.

Bustelo, P. (2004). El enfriamiento de la economía china en 2004. Boletín Elcano, (44), 5.

Bustelo, P., \& Fernández, Y. (1999). Resultados, interpretaciones y enseñanzas de la reforma económica china (1978-1998). Comercio Exterior, 49(7), 603-609.

Carrada-Bravo, F. (1996). Análisis comparativo de los mercados emergentes de Asia y América Latina. Comercio Exterior.

Cheng, L., \& Kwan, Y. K. (2000). The location of foreign direct investment in Chinese regions: further analysis of labor quality. In The Role of Foreign Direct Investment in East Asian Economic Development (pp. 213238). University of Chicago Press.

Chiñas, C. G., \& García, J. G. (2017). La presencia de China y México en las cadenas globales de valor. Una perspectiva crítica. Cimexus, 11(1), 67-85.

de Lucio, J. (2019). Liderazgo geopolítico: el papel de los acuerdos comerciales. Comillas Journal of International Relations, (15), 52-77.

Du, L., Harrison, A., \& Jefferson, G. H. (2012). Testing for horizontal and vertical foreign investment spillovers in China, 1998-2007. Journal of Asian Economics, 23(3), 234-243. 
Duana Ávila, D., \& Hernández Mendoza, S. L. (2012). Ventajas comparativas de China y México en el siglo XXI.

Dussel, E., Galindo, L. M., \& Loría, E. (2003). Condiciones y efectos de la inversión extranjera directa y del proceso de integración regional en México durante los noventa. Una perspectiva macro, meso y micro. Mexico: Plaza y Valdés.

Dussel, E., Galindo, L. M., Loría, E., \& Mortimore, M. (2007). Inversión extranjera directa en México: desempeño y potencial. Una perspectiva macro meso, micro y territorial. México, DF: Editorial siglo XXI, UNAM, Facultad de Economía, Secretaría de Economía.

Egger, P., \& Winner, H. (2005). Evidence on corruption as an incentive for foreign direct investment. European journal of political economy, 21(4), 932-952.

Galaso, P., Olivas, C., \& Díez, Á. S. (2016) La red de fusiones y adquisiciones transfronterizas como determinante de la inversión extranjera directa. Un estudio para América Latina en el periodo 1999-2012.

Galaso, P., Sánchez Díez, Á., García Gámez, S., \& Olivas, C. (2018). Los efectos de la red mundial de fusiones y adquisiciones sobre la inversión: un estudio para América Latina.

Garay, A. (2012). Inversión Extranjera Directa. Diccionario crítico de empresas transnacionales. Claves para enfrentar el poder de las grandes transnacionales, Icaria, Barcelona.

Garrido N., C. (2001). Fusiones y adquisiciones transfronterizas en México durante los años noventa. Naciones Unidas, CEPAL, División de Desarrollo Productivo y Empresarial.

Garriga, A. C. (2017). Inversión extranjera directa en México: comparación entre la inversión procedente de los Estados Unidos y del resto del mundo. Foro internacional, 57(2), 317-355.

Garriga, A. C. (2017). Inversión extranjera directa en México: comparación entre la inversión procedente de los Estados Unidos y del resto del mundo. Foro internacional, 57(2), 317-355.

Giner, G., \& Giner, J. M. (2002). La inversión extranjera en China: análisis y políticas. Boletín económico de ICE, 2733.

Head, K., \& Ries, J. (2004). Exporting and FDI as alternative strategies. Oxford Review of Economic Policy, 20(3), 409-423.

Jiménez, B., Celina, G., \& Aristarco, R. P. (2016). Tierras, minas y crecimiento demográfico. Calvo Thomas, Regalado Pinedo Aristarco,(coords.), Historia del Reino de la Nueva Galicia, Universidad de Guadalajara, 458.

Mathur, A., \& Singh, K. (2013). Foreign direct investment, corruption and democracy. Applied Economics, 45(8), 991-1002.

Mollick, A. V., Ramos-Duran R., y Silva-Ochoa E. (2006) "Infrastructure and FDI Inflows into Mexico: A Panel Data Approach”, Global Economy Journal, vol. 6, núm. 1, 2006, pp. 1-25.

OEC (2016)https://oec.world/es/visualize/tree_map/hs92/export/chn/show/all/2016

Ortega, P. G. (2015). Política nacional e inversión extranjera directa en México en el entorno internacional/National policy and foreign direct investment in Mexico in the international environment. RICEA Revista Iberoamericana de Contaduría, Economía y Administración, 4(8), 33-55.

Ortiz, J. (2013). Factores que afectan a la Inversión Extranjera Directa. Instituto de Investigaciones jurídicas. UNAM.

Panagariya, A. (2013). India and China: trade and foreign investment. Economic reform in India: Challenges, prospects, and lessons, 96.

Poulsen, L. S., \& Hufbauer, G. C. (2013). Foreign direct investment in times of crisis. Transnational Corporations, 20(1), 19-37. 
Ren, S., Yuan, B., Ma, X., \& Chen, X. (2014). The impact of international trade on China' s industrial carbon emissions since its entry into WTO. Energy Policy, 69, 624-634.

Salas, L. L. (2006). Determinantes y efectos de la inversión directa extranjera en China. Economía industrial, (362), 79-92.

Salvador, A. (2012). El proceso de apertura de la economía china a la inversión extranjera. Revista de Economía Mundial, (30), 209-231.

Sánchez Ortiz, A. (2018). El rol de las políticas e instituciones en la evolución de la inversión extranjera directa: casos de China y México. México y la cuenca del pacífico, 7(19), 61-92.

Scheel, C., \& Pineda, L. (2015). Innovacities: Impacto de los sistemas regionales de innovación en las estrategias competitivas de las ciudades. Universidad Jorge Tadeo Lozano.

Qu, T., \& Green, M. B. (2018). Chinese foreign direct investment: A subnational perspective on location. Routledge.

Wang, J. (2013). The economic impact of special economic zones: Evidence from Chinese municipalities. Journal of development economics, 101, 133-147.

Vera, C., y Machinea, J. L. (2006). Comercio, inversión directa y políticas productivas. CEPAL.

Zebregs, H. (2003). Foreign direct investment and output growth. China: Competing in the Global Economy, 89100. 